\title{
Superconducting Magnet System for the TPX Tokamak
}

W.V. Hassenzahu, M.R. Chaplin, J.R. Heim, D.D. Lang,

T.G. O'Connor, D.S. Slack, R.L. Wong, J.P. Zbasnik, T.G. Brown, J.C. Citrolo, D.B. Montgomery, L. Myatt, R.D. Pillsbury, J.H. Schultz, and P.W.Wang

This paper was prepared for submittal to the Thirteenth International Conference on Magnet Technology Victoria, British Columbia, Canada September 20-24, 1993

September 15, 1993

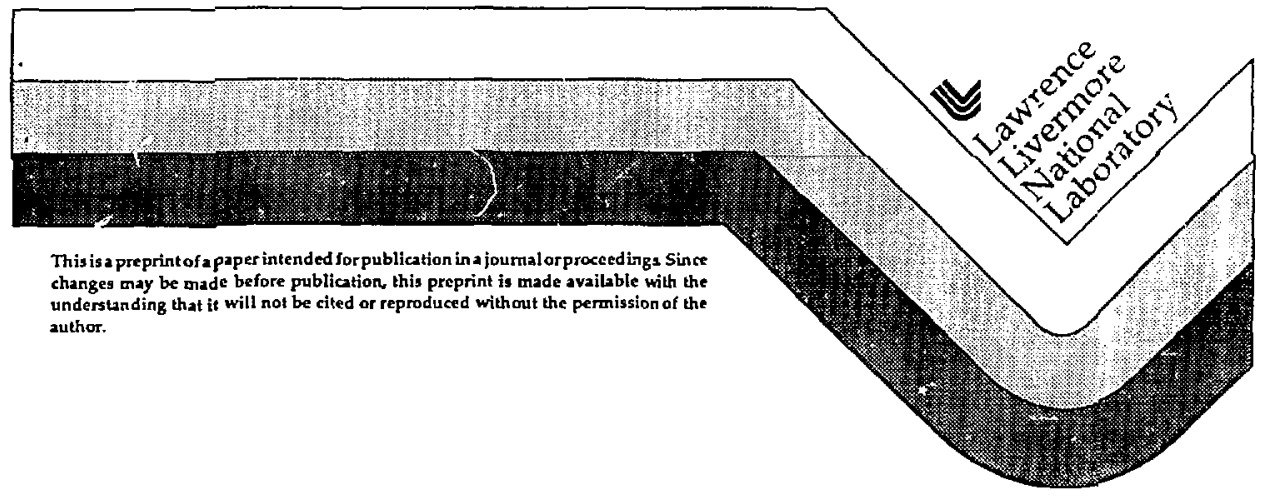




\section{DISCLAINER}

This docunient Hes prepared as an account of work sponsored by an ogency of the United States Govemiment. Neither the United States Govermment nor the University

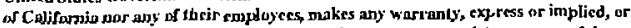
assumes any legal linbility or responsibility for the accuracy, completerness, or usefulness of any information, apparatus, product, er process disdosed, or represents that its use would not infringe privulcly onned rights. Reference herein to any specificcommercial products, frocess, or service by erade name, trademark, manufacturer, or oherwise. dees her necessarily constitute or imply ils efdorsement, recommendation, or fevoring by the United States Govenment or the Cniversity of Califomia. The vitws and opinions of authors expressed herin do not necessarily stal:* or reflect those of the Unitad States Govenument ar the University of Califomio, and shall not the used for advertising or product endorsement purposes. 


\title{
Superconducting Magnet System for the TPX Tokamak
}

\author{
W. V. Hassenzahl, M. R. Cbaplin, J. R. Hcim, D. D. Lang, J. G. O'Connor, \\ D. S. Slack, R. L. Wong, and J. P. Zbasnik \\ Lawrenee Livermore National Lahoratory \\ P.O. Box 808, L-643 \\ Livermore, $\mathrm{CA} 94551.9900$ \\ T. G. Brown and J. C. Citrolo \\ Plasma Physics Laboratory, Princeton University \\ P.O. Box 451 \\ Princeton, NJ 08543 \\ D. B. Montgonicry, L. Myalh, R, D. Pillsbury, J. H. Scbulk, and P. W. Wang \\ Massachusels Instituie of Technology, Plasma Fusion Center \\ 175 Albany Strect, NW17-288 \\ Cambridge, MA 02139
}

\begin{abstract}
The Tokamak Physics Experiment (TPX) will be the first Tokamak using superconducting magnets for both the poloidal and toroidal ficld. It is designed for advanced Tokamak physics experiments in steacy-state and lotig-pulse operation. The TPX superconducting magnets use an advanced cable-in-conduit conductor (CICC) design similar to that developod in support of the International Thermonuclear Experimental Reactor (ITER). The toroidal field magnets provide $4.0 \mathrm{~T}$ at 2.25 $m$ witb a stored energy of $1.05 \mathrm{GJ}$. The poloidal field magnets provide $18.0 \mathrm{~V}$-s to imically start and rontrol long burns of a $2.0 \mathrm{MA}$ plasma.
\end{abstract}

\section{INTRODUCTION}

The Tokamak Physics Experiment (IPX) facility is key to the United States Magnetic Fusion Energy Devclopment Strategy, providing improvements in the Tokamak concept, as well as resolving key issues in the design and operation of steady-state reactors and plasmas [1], [2].

TPX has received initial DoE approval and will te built at the Princeton Plasma Physics Laboratory (PPPL). It is designed to run double-null, high-beta, and high-hootstrap fraction plasmas, as well as single-null plasinas at reduced parameters. Because the mission includes the achievement of steady-state and extremely long pulse operation at fult parameters, the use of superconducting coils to provide both toroidal and poloijal fields was an obvious candidate for the magnet system. The higher currem densities of the superconducting magnet system led to its selection over a much larger resistive magnet design. The only normal copper coils in the machine are internal to the vacuum vessel and, coupled with internat passive plates, conurol plasma vertical instabilities, while permitung plasma initiation.

The selection of an entirely superconducting coil system is significant for dic world fusion program. TPX will be the firsı Tokanak with a supcrconducting poloidal-field sysiem.
It will also be the firs: Tokamak in which all the coils use high-current, Cabic-In-Conduit Conduclors (CICC), as called for by the preliminary ITER designs. The topology of the superconducting magnet system is similar to those of NET [2] and the ITER CDA [4] magnets. The overall Tokamak configuration is shown in Fig. 1, and a reference set of major parameters and dimensions developed at the time of the Conceptual Design Review in March 1993 is listed in Table 1 . The details presented here may change, as the preliminary design of the superconducting magnets is still in progress. Early next year, a major part the design effort will be transferted irom the national laboratories to industrial parners who will eventually build the magnets.

\section{TOROIDAL.FTELD SYSTEM}

The TF system provides $4.0 \mathrm{~T}$ at the nominal $2.25 \cdot \mathrm{m}$ plasma operating point. It consists of sixteen coils in cases with wclded intercoil structures. Each coil consists of six double pancakes with a total of $84 \mathrm{mms}$. The conductor is based on that deyeloped for the US-DPC magnet [5] to benefit from prior manufaciuring, research, and develominent. The toroidal-ficld conductor ầ lows modest belium fractions, and hydraulic diamelers, improves the reliability of coil protection and reduces the cost of the cryogenic refrigerator. $A \mathrm{n} 11 \mathrm{~kW}$ refrigerator presently at LLNL will be inodified and moved to PPPI. For TPX use. The 33.5-kA conductor current is also a good match to existing power supplies at the PPII. site, requiring no additional rectifiers [1] and thercby achieving some cost reduction. Finally, a 33.5-kA conductor is a gond trade between the desires to kecp the current low (to ininimize lead losses) and to keep durnp and injtiation voltages low (Uhereby avoiding arcs). Toroidal-ficld magne chanacteristics are listed in Table 2.

The individual superconducting strands consist of a bighyield, relalively bigh-performance $\mathrm{Nb}_{3} \mathrm{Sn}$ composite with a high critical temperature. The $0.78-\mathrm{mm}$ diameler srands are cabled in a $90 \times 5$ paticril and inserted in a $2.4-\mathrm{mm}$

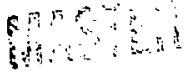




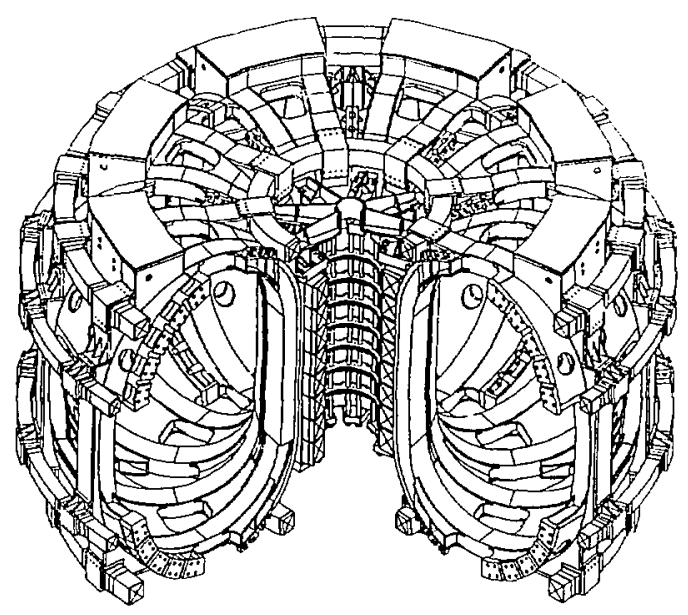

lig. 1. TPX Supcrconducting Magnet System

thick Incoloy 908 conduit. To reduce costs and minimize the number of joints, each TF coil is made from a single $-1000 \mathrm{~m}$ piece of conductor. Cooling is provided to each double pancake at the top outside radius of the winding. The TF Coil is wound and then reacted to form the $\mathrm{Nb}_{3} \mathrm{Sn}$. The TF coil pack is shown in Fig. 2.

The conisetor concept is a modification of the US-DPC wire, which combines relatively low cost with tested performance in pulsed fields. All surands are identical in the reference design, but an Rs 1 program, focused on current transfer, is qualifying a "hybri," cable design, where some triplets of strands in the 77 : coil contain one pure copper wire. If successful, it will provide a higher copper/noncolpper ratio for coil proteclion during a dump of the "TF systems and reduce the total conductor strand cost. Transient power balance hetween Joulc heating and heat transfer to the local

'TABLIE 1

TPX Tokamak Parimncters

\begin{tabular}{|l|l|l|}
\hline Parameter & Units & Value \\
\hline \hline$\overline{R_{0}}$ & $(\mathrm{~m})$ & 2.25 \\
\hline$a$ & $(\mathrm{In})$ & 0.5 \\
\hline$k$ & & 2.0 \\
\hline $\mathrm{B}_{l} @ \mathrm{R}_{0}$ & $(\mathrm{I})$ & 4.0 \\
\hline $\mathrm{I}_{\mathrm{D}}$ & $(\mathrm{M} \Lambda)$ & 2.0 \\
\hline heigh! & $(\mathrm{m})$ & 5.3 .3 \\
\hline diancter & $(\mathrm{m})$ & 8.73 \\
\hline
\end{tabular}

helium reservoir will allow recovery of quenched superonducting strands to assure stable operations.

While the pancakes are wound, steel or Incoloy 908 shims will be inserted as place-holders for the magsel insulation. The $\mathrm{Nb}_{3} \mathrm{Sn}$ coils are then heat treated without any insulation in the winding pack. After heat treatment. specially designed tooling is used to separate the turns in the pancakes. Each tum is wound with $0.4-\mathrm{mm}$ thick S-glass: tape. The sums ane returtied to the planc of the pancake and 0.8-mm thick glass-reinforced polyimide strips are insered between lums and pancakes. The coils are then cpoxy

JABLE: 2

T7. Magnet Perfonmance

\begin{tabular}{|c|c|c|}
\hline Paramcter & Inits & Dimensions: \\
\hline $\mathrm{B}_{\text {miax }}$ & (1) & 8.9 \\
\hline$l_{\text {cond }}$ & $(\mathrm{k} \wedge)$ & 33.5 \\
\hline$n_{\text {pancakes }}$ & & 12 \\
\hline$n_{\text {luvers }}$ & & 7 \\
\hline$n_{\text {coils }}$ & & 16 \\
\hline$n_{\text {turns, system }}$ & & 1344 \\
\hline$n_{\text {strands }}$ & & 450 \\
\hline$E_{m} \cdot 7 T^{\prime}$ & (ij) & 1.05 \\
\hline$V_{\text {dumin. svstem }}$ & $(\mathrm{kV})$ & 150 \\
\hline Tondectur & $(\mathrm{km})$ & 16.1 \\
\hline
\end{tabular}




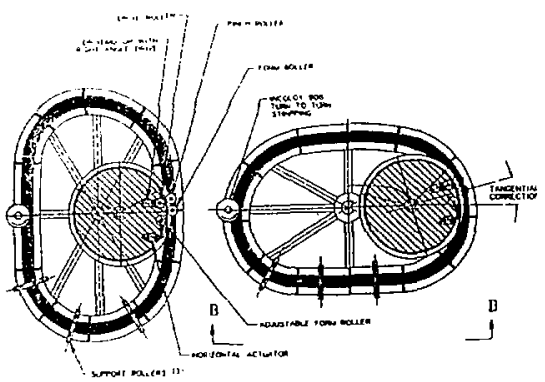

Fig. 2. TF Coil Winding Concept for TPX Sujcrconducting magnets, showing feed spool and conductor forming tooling.

impregnated under vacuum and pressure, and ground plane insulation is applied. Good contact between the windings and the cases of the TF coils is provided by high glass-content ероку, injected under pressure when the coil is installed in the cases.

The TF structure consists of welded 316 LN or 304 LN cases with thickened noses at the inside leg to support centering loads in wedging. A pair of coils is combined into a welded TF assembly with a central structural weldment and two identical closure welds. Two assemblies of two TF coils each, along with other Tokamak components, are then joired at the intercoil-strucurre parting plane with an insulated break joinc, to form a $90^{\circ}$ module. Figure 3 shows a two-coil assembly.

Suresses in the winding packs and cases have been $\checkmark$ calculated for in-plane and out-of-plane loads at the plasma end of bum (EOB). The bighest stresses occur in the port

1 segion, where the intercoil structure is constrained by the need for large borizontal ports between each TF coil, and in the nose region, where the radially inward magnetic forces are accomnodated with the wedged structure. In the preiliminary design, the peak stress is $490 \mathrm{MPa}$ in the port region and $560 \mathrm{MPa}$ in the nose region. The stresses occur in very small areas.

As in the present ITER design, the requirement of quench detection within is bas been adopted. Quench detectors will include a combiration of conventional medrods, such as voltage taps, intemal or extemal to the sheath, and pressure//low monitors, and experimental instrumentation. The goals of a quench delection R\&D program include uhe development of an insulated. co-wound conductor throught the center of cach cable and a fibre optic temperature sensor.

$A$ possible joint for the TF is the one developed for the US-DPC joint. It should be effective for the steady-state TF coils because of its low DC resistance of $0.4 \mathrm{n} \Omega$ at $30 \mathrm{kA}$, but will have to be shortened somewhat due to space constraints.

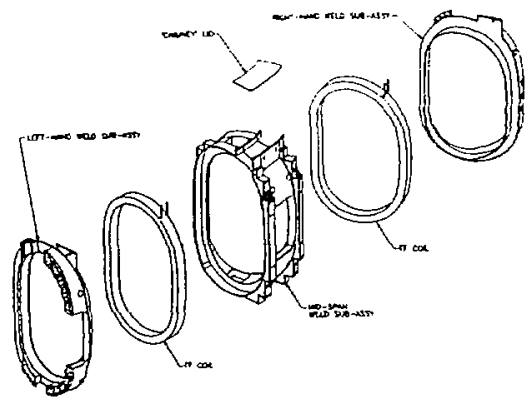

Fig. 3. TPX Module consisting of two coils, case and internal structure

\section{TIE POLOIDALFIIELD SYSTEM}

The TPX poloidal ficld system consists of 14 coils and is symmetrical about the vertical midplane and permits both single- and double-null operation. The Central Solenoid (CS) is suspended from the TF-coil structure. An uninsulated support structure, consisting of rods on the inside and pancls on the outside of the $\mathrm{CS}$ coil, prevents axial tension in the interpancake insulation and provides mechanical precompression to the stack. The $\mathrm{CS}$ is connected to the TF cases through a sliding comnection that permils differenlial radial motion of the two coil systems. Coils PF 5-7 are supportcd by brackets attachad to the TF cases.

The PF conductors are similar to those of the TF, using cable-in-conduit superconductors with cooling by forced-flow supercritical heliutn. A trade study showed that in contrast to the $T^{*}$ winding pack which prefers a bigh current density, the PF coils are optimized with a lower average current density to avoid the ficld concentration of a point source. Major dimensions of the PF syslem are listed in Table 3. The conductor and winding concept are similar to those shown in lig. 2 for the TF.

The PF-coils design uses all supercouducting cables and strands. However, if current-transfer experiments are successful, dic PF cable designs may also be replaced hy hybrid cables with one pure copper sirand in some triplets, in order to inprove cost and protection. 'The Nhy Sn composite strands in the CS and PI: 5 have a $3.5: 1$ copper/moncopper ratio. while the Nb-Ti strands are 5:1. Since the PF design is relatively low ficld, none of the coils see more than $7.5 \mathrm{~T}$. A trade study was performed lo exanine the cosverformance issucs in using Nb-Ti strands, instcad of Nbz̧Sn. Nb-Ti was more cost effective only in the outer ring coils, PF 6 and PF 7. Therefore, temary Nb3Sn is used in PF 1-PF 5 and $\mathrm{Nb}-\mathrm{Ti}$ in PF 6 and PF 7 . With the present design, the lead losses in the PF system are a third of the total refrigeration load. while the initiation voluges newer exceed $15 \mathrm{kV}$ or \pm $7.5 \mathrm{kV}$ u ground 
TABLE: 3

PF Magnet System Dimensions

\begin{tabular}{|c|c|c|}
\hline Parameter & Units & Dimcnsions \\
\hline$I_{\text {cond. max }}$ & $(\mathrm{kA})$ & 27 \\
\hline $\begin{array}{c}\mathrm{n}_{\text {strands }} \begin{array}{c}\mathrm{PF}[-4 \& 6-7 \\
\text { PF } 5\end{array}\end{array}$ & & $\begin{array}{l}225 \\
375 \\
\end{array}$ \\
\hline$w_{m}$ & $(\mathrm{MJ})$ & 118 \\
\hline$M_{\text {cond }}$ & (tonnes) & 50.1 \\
\hline lcond & (m) & 14.5 \\
\hline$B_{\max } \cdot P F$ & (I) & 7.5 \\
\hline$V-s_{\text {swins }}$ & (Wb) & 18.0 \\
\hline
\end{tabular}

A. central solenoid is a novel design baving alt coil terminations on the inner diameter. This faature minimizes the gap belween CS and the TF, and thereby maximizes the volt sccond - nux swing - capability, imporant features for smalt Tokomaks. The CS consists of eight modules to provide flcxibility far a variety of physics operating modes. Each rodulc is continuously pancake wound with no interpancake joints, as illustrated by Fig. 2 for the TF coils. Specially designed tooling will be used in order to wind the pancakes radially inward and outwand. The coils are fabricated with leads that extend to the service area below the Tokamak. The vertical and radial size of the lines and headers permit verical removal of the central solenoid without removing any other coils. Hydraulic inlet and outct fitlings follow the USDPC concept at altemating pancakes on the inside radius of each moaile. Each bydraulic line is connected through an electric isolator, similar to those proposed for the NET CS Model Coil[7], to vertically removable headers bolow the CS assembly. The PF cooling requirements are modest in IPX because of the long pulses, and the cooling system may be designed so that helium can move from the inlet to the outlet of a channel in less than one operating cycle. The central solenoid assembly, Icad and bydraulic circuit contiguration are shown in Fig. 4.

The Nb-Ti PE coils are wrapped with S-glass tape, during winding. Continuous strips of polyimide are cowound along with them, and polyimide disks are inserted between pancakes. Aiter winding all subsequent insulation, including impregnation, ground wrap, and fittings use the same sysiem as ube $\mathrm{Nb}_{3}$ inn coils.

\section{SUMNARY}

The IPX magnet system is designed in provide steadystate operation for advanced Tokamak physics experiments with inodest machine and operating costs. The IF and PF magnets are based on uemonstrated CIC-conductor concepts and also include new features that enhance the performance of superconducting magnets in Tokamak applications. Opcrational experience with an all supereonducting Tokamak in plasma scartup, disruption handling, and quench detection will be of value to ITJER and subsequent Tokannak reactors.

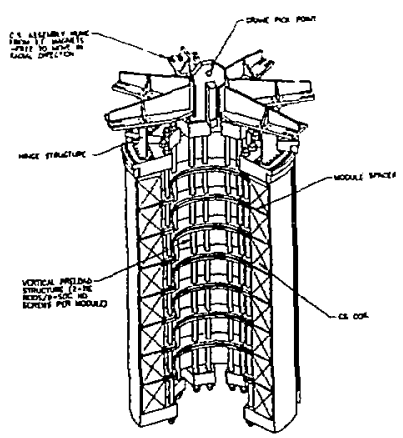

Fig. 4. Cenural Solenoid Assembiy

\section{ACKNOWLDGMENT}

This work was performed under the auspices of the U.S. Deparment of Energy by Lawrence Livermore Nationa] Laboratory under Contract W-7405-Eng-48.

\section{RIFERENCES}

[1] K.L. Thomassen et al, "Stcady-Statc Advancod Tokamak (TPX): Pre-Conceptual Design of a Supcrconducting TPX," Lawrence Livermore National Laboratory, UCRL-ID-1 10394, and G.H. Neilson et al, "Design of a Superconducting Steady State Advanced Tokomak," Proc. 17tt SOFT Conf., Rome. Italy, Pp 1636-1640, Scpt. 1992 .

(2) J.H. Schultz et al, "Superconducting Magnet System for the SSAT-S Tokomak", ibiul. pp. 932-936.

[3] J.R. Miller el al, IJZR MAGNET SYSTEM, ITTER MAGNET DESIGN UNI'I, IITER Documentation Series No. 26. IAEA, Vicnna, 1990.

[4] I. Butlura, F. Fardi, N. Mitchell, and M. Perrella. "Toroidal and poloidal tield coil concept design for NET." n. 1701, Symp. m Fusion Technology, Iondon. 1990.

[5] M.M1. Stecves et al, "Test results from the Mb3Sn USDemonstration Poloidal Coil," CEC-ICMC. Conf.. Huntsvilde, AL, June 1991.

[6] T. Painter et al, Tesi dita from the US-DIK experiment, PFCJRR-92.1, 3 1 1902.

[7] The NET Team, Concept Jefinition and Anaysis of the NEY Model Coils," N/R/6)221/1/2, 22.1.1901 